\title{
A comparison of the coping strategies method with stress among state and non state high schools students of the Karaj city ${ }^{1}$
}

\author{
Hamid Maleki \\ Department of Educational Management, Payame Noor University, \\ PO BOX 19395-3697, Tehran, Iran \\ E-mail address: Dr.h.maleki@gmail.com
}

\begin{abstract}
The present research deals with comparing coping strategies method with stress among state and non state high school students of the city of Karaj. This research $h$ which is descriptive and comparative includes 100 state and non state high school students of Karaj, who were as research samples chosen through the simple random sampling method. This research tool, was the questionnaire of coping strategies with stress among the adolescents (Freudenberg \& Lewis, 1993). Findings obtained suggest that there is a significant difference between state and non state high school students. Non state students scored higher in coping strategies who were categorized with respect to coping strategies grouping in the efficient group (concentration on solving problem, diligence and achievement, concentration on positive aspects) are salient characteristics of this group of people.
\end{abstract}

Keywords: Stress; Coping strategies to deal with stress; state schools; non profit schools

\section{INTRODUCTION}

Adolescence is a period of life that the first life experiences in the most critical period of the human growth occur. Providence, enthusiasm, education and future occupation, and identity determination are al formed in this period of time. Maybe, it is because of the fact that the psychology of adolescence has gained importance in the past decades and in particular in countries whose young population has been on the rise. Adolescence is a period of human growth stages which is thought to be the interface of the adolescence and childhood that its core features are puberty and appearance of sexual characteristic in the person. The age of starting puberty in accordance with cultural and social characteristics, environment and personal differences and in particular inheritance properties in societies, cities and even various families differ. In recent years, communication has been introduced as an effective factor in the premature puberty (Bowling, 1995). The impact of the environmental pressure among the adolescents, though not always, could result in negative consequences in the normal and personal functions, after the pressure ends. There is a complicated relationship between the material stressors and emotional and mental adaptations of the people. Environmental pressures have different results in the youth that are: offending people, mental

\footnotetext{
${ }^{1}$ This project was conducted with financial support PNU Alborz Province
} 
pressure, sleeping turbulence, anxieties, nervous and physical complaints, reduced educational functioning, lack of forbearance against frustration and increased blood pressure. When an adolescent is inclined towards a goal, when faces an obstacle, because his adaptations competence is affected by it, say mental pressure and stress are created. Sources of pressure could be internal and external deprivations. In other words, frustrations and conflicts that disrupt the mental status and personal normal, behaviors cause stress (Benzer et al, 2005).

The subject of controlling anxiety and stress has been at the focal point in recent years while the issue of stress has been widely determined. In this regards, clinical psychologists and others have examined the relationship between mental pressure and mental health. As a result, a broad range of the therapeutic methods are now available. Currently, controlling anxiety on the mental pressure in employed as a therapeutic manner in all service an health centers (Bowling, 1995). Today, the cognitive, behavioral therapeutic methods are so complicated that they can b called psychotherapy, while most of the therapeutic methods in order that they can be introduced practically an based on reality, should be tested. The orientation of this research is thought to be a communication bridge for the psychologists of different schools who are interested in controlling anxiety and stress (Benzer et al, 2005). Stress is said to be a disruptive and deterrent factor in the way of reaching one's own educational goals. A pressure generating reality resulted in the emotional behaviors free from rational adaptations with the environment. According to the personal differences existing among the humans, some students exposed to such environments will turn to behavioral patterns that are branded as restless, stubborn and difficult to control. It is possible for these stress making factors to render in the educational dropouts (Albert et al, 2010), resulting in the students to turn away from the schools. A percentage of the disruption cases (fear from school) could be traced in these stress generating factors deriving from the school environment.

Therefore, it is imperative that stress generating factors in the school and experimental environments be identified and examined so that the mental pressure on the young people is reduced and through creating suitable educational environments, a situation appropriate with the emotional, cognitive and social arenas be established (Alipour and Noorbala, 1999). Negative impacts of stress, generates a sense of lack of confidence, repulsion, anger and depression where these feelings culminate in such problems as headaches, stomach complaints, skin rash and itching, sleeplessness, stomach ulcer, high blood pressure, coronary illnesses and brain strokes. The death of a beloved and birth of a child will result inn the professional promotion and creation of a new stress relation, because these changes will coerce us to a new adaptation with life.

Adaptation with varying conditions depending on the way we respond could be either helpful and harmful .Identifying the continued stress and getting aware of its effects on our life are not sufficient for reducing its harmful impacts. As there are huge sources for stress, there are numerous ways to manage it (Benzer et al 2005). Unfortunately, depression and anxiety, often called as the illnesses of the century know no child or adults and all are subject equally to be afflicted with them. Most of the people are engaged with the problem of depression and anxiety in adulthood. However, the reality is that children an adults are equality prone to the affliction of these complaints. Furthermore, experts believe that since people don't think that the children suffer from stress, this disorder remains unknown among them (Alipour and Noorbala, 1999). When faced with anxieties, the young people will expose changes in their behavior. They often have rollbacks in their own behaviors while carry on things that they are not expected to do. When a stress making stimulus, activates the response 
of war and escape, heart beat will increase. All of these eventualities prepare the body for responding physically to the stress maker. However, in the modern world, the physical response is not a common coping way to deal with stresses that we face with them. Hence, physiological changes could lave lasting impacts on the body (Hunt et al, 2003). Stress will negatively affect the safety function.

Studies have shown that students by the time of examinations are more vulnerable to viruses. There is also a possibility that when people are under stress they get cold, because stress will weaken cells and antibodies that protect people from viruses (Hunt et al, 2003). Hormonal and cognitive safety changes that respond to stress are particularly followed by such symptoms as anxiety, depression and social loneliness and isolation. Studies carried out in the areas of loneliness impacts, failed marriages, marital severance, lack of social support, bereavement and stress deriving from illness have shown a significant relationship between these stress makers and changes to the hormonal levels, safety functioning and cognitive mental and emotional health (Rasooli, 2008). Given the increased anxiety disorders statistics among the youth, there is a need to conduct research on this phenomenon and attempts to identify it as well as eliminating the effective causes of it are felt (Ibid).

\section{RESEARCH METHOD}

The present research deals with comparing coping strategies method with stress among state and non state high school students of the city of Karaj. This research $h$ which is descriptive and comparative includes 100 state and non state high school students of Karaj (50 from state schools and 50 from non state schools), who were as research samples chosen through the simple random sampling method. This research tool, was the questionnaire of coping strategies with stress among the adolescents (Freudenberg \% Lewis, 1993). Findings obtained suggest that there is a significant difference between state and non state high school students. We then examined the answers of the students in the questionnaires and to analyze the data, we applied descriptive statistics (mean, standard deviation ) and also, the inferential statistics of the $\mathrm{T}$ tests was also employed.

\section{1. Tools to measure}

Questionnaire of coping strategies among adolescents was designed by Freudenberg \& Lewis, 1993 that is a five choice and eight article questionnaire. This tool was formulated by the two experts to measure coping methods among the youth aged from 12-18 based on the Lazarus theory. This form includes 18 scales and each scale includes a different coping strategy, these 18 coping strategies are grouped in 3 general coping styles showing the coping efficiency and inefficiency. First style: this style is called the style of solving problems or efficient coping and includes 8 strategies. Second style: is called referring to others that involves 4 strategies. Third style: also called the inefficient style of coping that includes 8 strategies. Freudenberg \& Lewis, 1993 showed the correlation of $0 / 44$ to $0 / 84$ after two weeks of retest in 18 subscales of this test whose validity is also reaffirmed . 


\section{2. Findings}

Table 1. Mean and standard deviation of the students' scores.

\begin{tabular}{|c|c|c|}
\hline Indexes & $\begin{array}{c}\text { State schools students' } \\
\text { scores }\end{array}$ & $\begin{array}{c}\text { No state schools students' } \\
\text { scores }\end{array}$ \\
\hline Number & 50 & 50 \\
\hline Mean & $206 / 86$ & $242 / 94$ \\
\hline Standard deviation & $59 / 412$ & $31 / 758$ \\
\hline
\end{tabular}

The mean of the coping strategies among the state school students is $(206 / 86)$ and the mean scores of the coping strategies among the non state school students is (242/94). Hence, the scores obtained in the state school students with respect to the coping strategies scales is lower than that of the non state school students.

Table 2. Correlated T scores.

\begin{tabular}{|c|c|c|c|c|c|}
\hline Sig. & df & T level & $\begin{array}{c}\text { Standard } \\
\text { deviation }\end{array}$ & Mean & $*$ \\
\hline $0 / 005$ & 99 & 2.921 & $68 / 596$ & 225.38 & state and non state \\
\hline
\end{tabular}

Given the above table, since the estimated $\mathrm{T}$ is greater than $\mathrm{T}$ (table of critical values ), we conclude that there is a meaningful difference between the two means at the $\alpha=0 / 005$ in the two groups. We assuredly takeaway that with $95 \%$ confidence level, there is significant difference.

\section{DISCUSSION AND CONCLUSION}

The present research deals with comparing coping strategies method with stress among state and non state high school students of the city of Karaj. This research $h$ which is descriptive and comparative includes 100 state and non state high school students of Karaj (50 from state schools and 50 from non state schools), who were as research samples chosen through the simple random sampling method. This research tool, was the questionnaire of coping strategies with stress among the adolescents (Freudenberg \% Lewis, 1993).

Findings obtained suggest that there is a significant difference between state and non state high school students. We then examined the answers of the students in the questionnaires and to analyze the data, we applied descriptive statistics (mean, standard deviation) and also, the inferential statistics of the $T$ tests was also employed. Given the above table, since the estimated $\mathrm{T}$ is greater than $\mathrm{T}$ (table of critical values), we conclude that there is a meaningful difference between the two means at the $\alpha=0 / 005$ in the two groups. We assuredly takeaway that with $95 \%$ confidence level, there is significant difference. Non state students scored higher in coping strategies that were categorized with respect to coping strategies grouping in the efficient group (concentration on solving problem, diligence and 
achievement, concentration on positive aspects) are salient characteristics of this group of people. The complicity of human civilization and social relations has caused new stresses that against which each person should be prepared. When the young people face with anxiety they expose wrong conducts and do what they are not expected to do, hence they have repulsions. Of the environments that can help students to reduce their level of stress making behaviors is school that could through introducing and implementing programs prevent stress and depressions and raise coping strategies to deal with these problems.

\section{References}

[1] Albert U., Mania G., Bogetto F., Chiarle A., Mataix-Cols D., Comprehensive Psychiatry 51 (2010) 193-200.

[2] Alipour A., Noor Bala, Ahmed Ali. A preliminary study on the reliability and validity Oxford Happiness Questionnaire, The University of Tehran Journal 2 (1978) 65.

[3] Bowling A., The concept of quality of life in relation to health, medicine neisecoli, Bulletin of the World Health Organization 82 (2004) 63-645.

[4] Statistics, Iran Statistical Yearbook, Tehran. Planning and Budget Organization. 1990.

[5] Ben-Zar H., Dudevany H., Lury L., Journal of intellectual Disability Research 49(1) (2005) 45-62.

[6] Hunt S., Wisocki P., Yanko J., Journal of Anxiety Disorders 17 (2003) 560-547.

[7] Koran L. M., Bromberg D., Hornfeldt C. S., Shepsker J. C., Wang S., Hollander E., Comprehensive Psychiatry 24 (2010) 1-17.

[8] Maddi S. R., Journal of Positive Psychology 1 (2006) 160-174.

[9] Rasouli Z. (1988). Emotionalintelligence trainingeffectiveness, happiness and quality of Lifein postmenopausal women Rasht City. MS Thesis, Payame Noor University, Tehran. 